\title{
LA HISTORIOGRAFIA ECONOMICA \\ DE MEXICO *
}

JOHN H. COATSWORTH

The University of Chicago

No cabe duda alguna de que la pasada década ha presenciado un extraordinario avance en la historia de la actividad económica mexicana. Gran parte de lo que creíamos saber en 1976 ha quedado reducido a notas a pie de página, que dan fe del abandono de ideas erróneas y de la adquisición de nuevos conocimientos. En su mayoría, los avances que con buen acierto celebramos no se deben, como cabría esperar, ni a los que practican lo que seguíamos llamando "nueva" historia económica hasta hace un decenio, ni a los teóricos esquemáticos de los cuales tomamos aquellos rimbombantes subtítulos con que una vez decoramos nuestros manuscritos. Este ámbito ha avanzado, por el contrario, en virtud de una sostenida acumulación de historias institucionales, financieras y regionales que han proporcionado abundantes datos nuevos y juicios más afinados sobre una amplia gama de cuestiones. $Y$ ha avanzado también como consecuencia de la compilación y publicación de nuevas series de información cuantitativa que sólo recientemente han empezado a explotar los historiadores.

Acaso el fenómeno más interesante, aunque debatible, de la década precedente haya sido el descubrimiento de que el desfase de productividad existente entre México y los países desarrollados no ha cambiado en los últimos cíen años '. Desde el Porfiriato, la renta per capita mexicana ha aumentado aproximadamente en la misma proporción que la de Estados Unidos o Europa occidental; aunque algo más rápidamente a fines del siglo XIX y tras la II Guerra Mundial, y más lentamente durante la Revolución y la década de 1920 , en términos generales la economia mexiçana ha crecido al mismo ritmo que las de los países industriales a partir de la década de 1870. Para expresarlo de otro modo: sabemos hoy que la magnitud del desfase que

* Versión española, con pequeñas modificaciones, del trabajo leído en la reunión de la American Historical Association (Conference of Latin American History, Committee on Mexican Studies), el 29 de diciembre de 1986.

1 Coatsworth (1978), 80-100. 
separa la economía de México de las de las naciones desarrolladas se debe exclusivamente al atraso relativo del país en los albores de la época contemporánea, y no se debe en modo alguno a los efectos supuestamente perniciosos del imperialismo y la dependencia actuales ${ }^{2}$.

Podrá parecer perverso resaltar el éxito de la economía mexicana en el siglo $\mathrm{xx}$, dada la crisis de los últimos años. En efecto, es posible que los futuros historiadores interpreten los años ochenta como un período crítico de discontinuidad, en que se agotaron (aunque yo tengo mis dudas) los beneficios de la dependencia anterior. No obstante, semejante observación tiene el efecto positivo de asignar un gran nivel de importancia a la historia económica de un pasado remoto, y por ello al tema de este artículo. Si en algún momento los políticos o el público en general llegan a descubrir el motivo de que la actual renta per capita de México oscile entre una séptima y una octava parte de la de Estados Unidos, serán los historiadores del período colonial. y la independencia los que habrán de decírselo.

Mi trabajo recorrerá, por tanto, a gran velocidad, tres siglos y medio de historiografía económica reciente en busca de claves. En primer lugar pasaré revista a lo que sabemos sobre las tendencias de la actividad económica agregada, concentrándome primordialmente en aquellos trabajos que, contribuyan a formular conjeturas ponderadas sobre los cambios a largo plazo en rentas y productividad. Al repasar las obras recientes, intentaré destacar en la misma medida lo que aún no sabemos y lo que se ha descubierto. Y espero que ello pueda, asimismo, formar la base de una sección final que contenga la obligada lista de protestas metodológicas, temas de tesis doctorales y oportunidades de inversión para las fundaciones privadas.

${ }^{2}$ Posiblemente merezca la pena registrar dos caveats sobre esta afirmación, entre los muchos que podrían apuntarse. Primeramente, no tiene la finalidad de rebatir la hipótesis de que México pudiera haber crecido más rápidamente bajo una serie de condiciones plausibles contrafactuales, según las cuales el país habría asimilado tecnología extranjera (y comenzado a producir avances técnicos pertinentes por sí mismo) a menor coste. No tiene tampoco la intención de atacar la idea, recientemente reformulada por Enrique Semo, de que la revolución mexicana de 1910 fomentó el crecimiento económico mexicano al reducir la influencia política de la oligarquía terrateniente, que en otros casos latinoamericanos se unió a los intéreses extranjeros para producir un entorno político más hostil a la industrialización, reduciendo con ello el potencial progreso económico. Véase Semo (1975), 49-61. En segundo lugar, el hecho de que las economías mexicana y norteamericana hayan crecido (a largo plazo) aproximadamente al mismo ritmo, nada indica sobre los costes sociales de este avance en ambos países, ni debe ser aportado como prueba de la conveniencia de una política pública que no consigue rectificar las desigualdades en la distribución o las deficiencias en la formación de capital humano. 
Voy a comenzar con la disputa más prolongada en los anales de la historia económica mexicana: el debate, aparentemente interminable, sobre la supuesta depresión del siglo xvir. Como cualquier estudioso sabe, la depresión del siglo xviI fue descubierta hace treinta y cinco años por Woodrow Borah ${ }^{3}$. Tras múltiples tomas y dacas, Herbert Klein y John TePaske_reanimaron la polémica en su artículo de 1981 publicado en Past and Present, en el que ponían en tela de juicio la hipótesis de la depresión demostrando que los ingresos fiscales permanecieron más o menos constantes, y no en descenso, entre 1600 y $1699^{4}$. Puesto que las rentas no decayeron, tampoco decayó la economía. La depresión era simplemente un estancamiento.

Curiosamente, el debate que siguió al artículo no se centró en las debilidades más importantes de su argumentación, la mayoría de las cuales habían sido reconocidas previamente por sus autores, que se mostraron perfectamente dispuestos a tratar la cuestión a un nivel, de decibelios mucho más bajo del que más adelante alcanzó.

Klein y TePaske sostenían que las tendencias a largo plazo de las rentas fiscales reflejan cambios auténticos en el nivel de actividad económica ${ }^{5}$. La fuerza de su razonamiento estribaba en una observación elemental: que la razón entre rentas gubernamentales y producto nacional bruto ha tendido históricamente a permanecer muy estable en todos los países para los que disponemos de datos, a lo largo de períodos de tiempo muy prolongados, al menos hasta el siglo xx. Asi pues, es probable que el margen de error inherente al uso de las tendencias en rentas gubernamentales como indicador de las tendencias del PNB sea reducido, salvo en períodos breves de crisis o guerra.

Esto no significa, no obstante, que los datos de Klein-TePaske puedan aceptarse sin cuestionar. Los datos fiscales muestran tendencias nominales más que reales. Es decir, como ambos autores manifestaron clara y explícitamente, no pudieron rectificar sus datos para incorporar los efectos de la inflación (o deflación), porque nadie ha elaborado aún un índice de precios adecuado para la economía mexicana del siglo xvir ${ }^{6}$. Si el nivel de precios de Nueva España se hubiera duplicado simplemente entre 1600 y 1699 , los datos fiscales de estancamiento de Klein-TePaske habrían ocultado un descenso del 50 por 100 en rentas fiscales reales (y por tanto en PNB). Para duplicarse en 100 años, los precios tendrían que haber aumentado a una tasa media del 0,7 por 100 anual solamente. Afortunadamente para ellos, los pre-

${ }^{3}$ Borah (1951).

Klein y TePaske (1981), 116-135. Véanse, también, los ensayos críticos de Kamen e Israel, con la «contrarréplica» de Klein y TePaske (1982), 144-161.

s Ibid., 119.

- Ibid., 118. 
cios del siglo xvir del resto del mundo muestran una extraordinaria estabilidad ${ }^{7}$.

Pero surgió otra complicación más grave. Supongamos que el nivel de precios de Nueva España no hubiera sufrido ninguna alteración en el siglo xvir. Continuemos suponiendo que las rentas fiscales fueran una proporción constante del PNB en este mismo período. Incluso con estos supuestos, sería muy posible que los datos fiscales confirmaran, en lugar de refutar, la hipótesis de la depresión. Si las rentas fiscales, y por consiguiente el PNB, se estancaron, mientras se duplicaba la población mexicana (como prácticamente ocurrió al parecer) ${ }^{8}$, entonces el producto per capita tuvo que reducirse a la mitad en el siglo xvir. Ĺa productividad de la economía de 1699 sería la mitad de la de 1600 . También esta posibilidad había sido prevista por ambos autores, que con todo cuidado definieron «depresión» como un descenso de la actividad económica total (en lugar de per capita) ${ }^{9}$. Ahora bien, en este caso pisaban terreno menos firme. Es el producto per capita y no el total el que proporciona al économista y al historiador su mejor indicio (si bien imperfecto) de la productividad y, por ende, la salud de una economía.

Pero hay más. Según parece, el desafío Klein-TePaske a la hipótesis de la depresión sólo puede sostenerse si se abandona el supuesto de que las rentas fiscales reflejan adecuadamente la tendencia de la economía en su totalidad. Estos autores suponen que las tendencias del sector que producía artículos imponibles eran equivalentes a las tendencias del sector que no satisfacía impuestos. Dos terceras partes_o más de todos los artículos y servicios producidos en el siglo xvil en Nueva España escapaban al recaudador de impuestos, por lo que resulta una hipótesis un tanto desmedida ${ }^{10}$. (Dejemos a un lado, por el momento, el tributo indígena, que era un impuesto por cabeza más que sobre artículos o servicios.) ¿Tenemos seguridad de que la decadencia del sector hispano-mestizo de la economía, fuertemente gravado (según se deduce de los datos de Klein-TePaske, que muestran un descenso a largo plazo de las rentas fiscales per capita) estuvo acompañado por una similar decadencia a largo plazo del sector no gravado de la economía del

${ }^{7}$ Braudel y Spooner (1967), 392-407.

- No abundan los cálculos de población para el siglo xvir en Nueva España. Véanse Borah (1951), 33; Borah y Cook (1960), y, de los mismos autores, (1979), vol. 2, cap. 2. Véase, también, Aguirre Beltrán (1946).

- Klein y TePaske (1981), 119-120.

10 Yo calculo que en 1800 la agricultura sólo producía alrededor del 40 por 100 del PIB (aunque este sector daba empleo probablemente al 80 por 100 de la población activa); véase Coatsworth (de próxima aparición). En los siglos xvi y xvir, con una proporción muy inferior de europeos y mestizos y un mayor sector de subsistencia indígena que producía tanto alimentos como otros productos indispensables, dos terceras partes parece ser una conjetura adecuada. Cualquier observación será bien recibida. 
siglo xvII, en su mayoría no español, y predominantemente de subsistencia? $\mathrm{Si}$ es así, la hipótesis de una fuerte depresión queda considerablemente reforzada por los datos fiscales que Klein y TePaske presentaron para rebatirla. Si no, su supuesto metodológico se desmorona, pero pueden rescatarse sus resultados empíricos.

Supongamos, por ejemplo, que la decadencia de las propiedades territoriales y de las industrias españolas, iniciada en las décadas de 1620 y 1630 , coincide con el aumento de bienestar y productividad de la población india, puesto que los braceros que en su día fueron obligados a trabajar para españoles y criollos pudieron entonces velat por sus propios intereses. Podría especularse que el hecho se produjo basándose simplemente en los datos demográficos, pues lo cierto es que fue durante la depresión del siglo XVII cuando empezó a crecer nuevamente Ta población indigena ". La evidencia fiscal de decadencia sólo podría medir, pues, la depresión en producción gravable, apenas un tercio del PNB. El 50 por 100 de un tercio es solamente un 17 por 100. Para salvar la hipótesis de estancamiento de KleinTePaske, por tanto, sólo habría que suponer que el incremento en productividad del sector no gravado de la economía gracias a la abolición o atenuación del trabajo forzado indígena, fue suficiente para compensar esta pérdida en productividad del $17^{\prime}$ por 100 del sector que pagaba impuestos.

Si se abandona la hipótesis de que las rentas reflejan tendencias económicas, podría salvarse la tesis del estancamiento del siglo xviI, pero quedaría, simultáneamente, en cuestión la hipótesis implícita de que la prosperidad había caracterizado la época precedente. En el mercado dual de trabajo de los años posteriores a la conquista, se obligó a los indios a dedicar una parte mayor de su tiempo a trabajar en las empresas europeas de lo que hubieran hecho sin elemento de obligatoriedad. Al margen de las distorsiones que suponía la asignación política de obreros forzados una vez destinados al sector europeo (no parece probable que los jueces de reparto distribuyeran la mano de obra entre los empresarios ni siquiera con la eficacia de un mercado imperfecto), el paso de la mano de obra de los sectores indígenas a los europeos redujo probablemente la productividad total de la economía de la colonia (así como el bienestar de los indios). Abandonados a sus propios recursos, los indios habrían invertido su trabajo allí donde la productividad y el bienestar - y con ello los beneficios que más estimabanfueran más altos.

Tendremos, así pues, que indagar en qué medida fueron perjudiciales para el crecimiento de la economía los efectos del trabajo forzado sobre la productividad del sector.indígena en el siglo xvi, y confrontar esta pér-

\footnotetext{
"Véase nota 9.
} 
dida con los efectos negativos que tuvo la abolición de esta clase de trabajo sobre la productividad del sector europeo posteriormente. Si los datos de las rentas fiscales (o la producción agraria, o el comercio) tienden a exagerar la magnitud de la depresión del siglo xvir a partir de 1630 , las elevadas rentas del siglo xvi y principios del xviI pueden habernos inducido a formarnos una imagen exagerada de la prosperidad de este último período. Borah y Cook han demostrado que la despoblación permitió a los indios que aún quedaban reconcentrarse en las tierras más productivas, aumentando así la productividad de la agricultura indígena ${ }^{12}$. En efecto, al trasladar a los indígenas a las haciendas, minas y obrajes europeos, los administradores españoles lograron mayores rentas fiscales (porque las propiedades europeas producían mercancía gravable), pero al precio de transferir mano de obra de una actividad más productiva a otra que lo era menos. Así pues, los datos fiscales del siglo xvi podrían estar reflejando una falsa prosperidad, generada al concentrar por coacción a una proporción cada vez mayor de la menguante población indígena en las empresas europeas, en detrimento de la productividad económica en general. Podría ser, por consiguiente, que TePaske y Klein tuvieran razón después de todo, y precisamente por los motivos contrarios. Acaso no hubiera tal depresión en el siglo xvir porque no hubo prosperidad en el xvi.

¿Cómo queda el debate sobre la depresión del siglo xvir una vez dicho esto? Pues aún muy necesitado de nuevos modelos y nuevos datos. Por el momento, parece al menos plausible concluir que no se produjeron alteraciones decisivas en la productividad de la economía mexicana entre finales del siglo XVI y finales del xvir. Dado que los historiadores de las economías de Europa occidental han descubierto períodos más o menos prolongados de estancamiento y decadencia durante estos mismos años ${ }^{13}$, podríamos concluir también de modo tentativo que el desfase entre México y el mundo desarrollado no se originó (o al menos no aumentó) durante el siglo xvir.

\section{* * *}

El debate en torno a las tendencias de la actividad económica del siglo xvirI suscita igualmente cuestiones metodológicas y esenciales, pero sobre un distinto contexto histórico e historiográfico. El contexto histórico difiere en la abundante evidencia de expansión económica. Y el historiográfico difiere, de modo similar, en ia profusión de obras monográficas, así como generales, que han aparecido en el último decenio.

Como en el caso del siglo xvir, los datos fiscales de Klein-TePaske han generado un debate sobre tendencias macroeconómicas. Pero, a diferencia

${ }^{12}$ Borah y Cook (1979), vol. 3, 172-173.

is Véase Parker y Smith (1978). 
del siglo xvir, dicho debate es nuevo. Hasta el estudio de Florescano sobre el precio del maíz en la Ciudad de México en el siglo xviII ${ }^{14}$, prácticamente todos habían aceptado la calificación convencional de «siglo de oro" para esta época. Incluso en las obras posteriores de Florescano se conservaba esta caracterización, y se trataban las «crisis» agrarias más como episodios de causas climatológicas que como síntomas de una dolencia económica más profunda ${ }^{15}$. Actualmente, tres tipos de trabajos han cuestionado esta opinión convencional, de los que se desprende que la expansión económica pudo interrumpirse, al menos sufrir una fuerte reducción en su ritmo de avance, ya a fines de la década de 1770 , un cuarto de siglo antes de que estallaran las guerras de independencia, en las que suele fecharse la catástrofe mexicana del siglo xix. En primer lugar, hay estudios regionales y de ciertas empresas donde se ofrecen datos que pueden interpretarse (a veces contrariamente a las intenciones de sus autores) como indicio de unos niveles de productividad en descenso o estancamiento en la miseria, la agricultura y la industria a fines del siglo xviII ${ }^{16}$. El caso más sobresaliente es el de la industria minera. El estudio de Brading sobre el boom minero del período post-Gálvez, presentaba en realidad abundante evidencia de las dificultades que acosaban a las compañias mineras. Por parte de la oferta, se estaban elevando los costes porque los empresarios de muchos centros tuvieron que profundizar los pozos e incrementar la inversión en obras de drenaje cada vez más dispendiosas para llegar hasta un mineral de calidad cada vez más baja. Por parte de la demanda, se estaban elevando los precios de la mayor parte de los artículos adquiridos con la plata así producida, o, para decirlo de otro modo, estaba descendiendo el precio de la plata. El aumento de los costes por unidad y el descenso de los precios en descenso por unidad colocaron a la industria minera en un clásico aprieto. Aumentó el producto físico (aunque en proporción inferior a anteriores décadas) parcialmente debido a que se tomaran medidas públicas con objeto de apoyar e incluso subvencionar esta industria ${ }^{17}$.

En segundo lugar, existen indicios de un descenso en productividad agrícola en el campo mexicano rayano en una crisis malthusiana, a fines del siglo xviri. El mejor resumen de la evidencia existente a este respecto se encuentra en el brillante ensayo de Eric van Young sobre lo que él ha denominado "paradojas" de la agricultura mexicana en las postrimerías del período colonial, publicado recientemente en una excelente antología de tra-

\footnotetext{
${ }^{14}$ Florescano (1969).

is Véase Florescano y Gil (1976), 183-301.

16 Entre los ejemplos más notables figuran Brading (1971), 26-45; Van Young (1981); Morin (1979), y Salvucci (1987).

17 Vease Coatsworth (1986), 26-45.
} 
bajos sobre las economías de México y Perú durante dicho periodo (Fbe Economies of Mexico and Peru During the Late Colonial Period), editado por Nils Jacobsen y Hans Jurgen Puhle ${ }^{18}$. Hay otros estudios regionales que contienen datos que apuntan también en este sentido, aún si en muchos casos dichos datos quedan para ser interpretados por otros ${ }^{19}$. $\mathrm{Y}$ a los trabajos sobre la agricultura, podría añadirse una lista en aumento de obras sobre la industria, el comercio y la política pública coloniales, que llegan a conclusiones similares (o proporcionan datos que coinciden con ellas) con respecto a otros sectores de la economía ${ }^{20}$.

Y finalmente, claro está, existen los datos fiscales que han suscitado la polémica explícita sobre las tendencias macroeconómicas. Para el siglo xviII, Klein y TePaske han elaborado ensayos individuales cuyas conclusiones vienen a ser en cierta medida similares ${ }^{21}$. TePaske fecha la decadencia de fines del período colonial a partir de los últimos años de la década de 1770 o en la de 1780 , mientras que Klein se inclina por la de $1790^{22}$.

Si la depresión de fines de siglo parece estar ya bien establecida, el ritmo y la forma de la expansión económica previa a la década de 1780 sigue siendo objeto de polémica. La cuestión primordial se refiere a las posibles fuentes de crecimiento de la productividad. Los contados historiadores que han planteado esta cuestión explícitamente, han llegado a conclusiones similares: que la expansión económica del siglo XviII no fue, en términos generales, resultado de avances en la productividad. Por el contrario, la economía se expandió con un nivel prácticamente estancado de producción per capita. El aumento demográfico proporcionó más trabajadores a la población activa pero no los hizo más productivos. Las explotaciones agrícolas acrecentaron sus tierras, alteraron su producción o invirtieron capital empleando tecnologías tradicionales, pero la «productividad -es decir, la capacidad relativa de producción de una unidad determinada de capital, trabajo o tierra- parece haberse estancado o aumentado escasamente», según lo expresa Van Young ${ }^{23}$. En la minería, Brading concluyó que fueron mínimos los cambios tecnológicos y de los mejores datos disponibles se desprende que a fines del siglo xviII la producción por obrero en las minas

18 Van Young (1986), 64-90.

19 Véanse los trabajos de Brading, Morin y Van Young citados en la nota 16. Véanse, también, Galicia (1975); Lindley (1982); Pastor et al. (1979); Taylor (1972).

${ }_{20}$ Véanse los trabajos de Brading y Salvucci citados en la nota 16. Véanse, también, Thomson (1986), 169-202; Coatsworth (1982), 25-51.

21 TePaske (1986), 316-339; Klein (1985).

22 TePaske (1986); Klein (1985). La diferencia de tiempo se debe a la decisión de TePaske de deflactar los datos fiscales para eliminar los efectos de la inflación de precios; Klein utiliza series sin rectificar.

${ }^{23}$ Van Young (1986), 64. 
mexicanas pudiera no ser superior a las de Perú ${ }^{24}$. También se estancó la tecnología industrial, ségún Salvucci, en los tejidos de lana ${ }^{25}$; en los de algodón, según la hipótesis de Thomson ${ }^{26}$. Del interesante, si bien «tosco» y «altamente especulativo», esfuerzo de TePaske por elaborar estimaciones de renta per capita utilizando datos fiscales para extrapolar mis estimaciones de 1800 retrospectivamente para el siglo xviII, se extraen conclusiones algo distintas. Ahora bien, la estimación que él prefiere produce una renta per capita para 1800 que es sólo un 14 por 100 superior a la de la década de $1740^{27}$.

Pero se puede lograr un incremento de productividad de modos diversos, no solamente mediante la aplicación de nuevas tecnologías. North y Thomas sostuvieron en una ocasión, por ejemplo, que la mayor eficacia en los mercados y en la organización económica había sido uno de los orígenes más importantes del aumento de productividad en Europa occidental a comienzos de la edad moderna ${ }^{28}$. Existe cierta evidencia, al menos, en las obras recientes sobre México, de que las_economías de escala, unos menores costes de información y transacción, mayor movilidad de los factores, nuevas formas organizativas, medios crediticios nuevos o más ampliamente asequibles, y otros cambios similares pueden haber fomentado una mayor productividad en el México del siglo xvirI ${ }^{29}$. Sin embargo, es posible que esta tendencia positiva quedara anulada por el crecimiento de la burocracia, los monopolios del Estado, la extorsión fiscal, y normativas gravosas, especialmente hacia fines del siglo. Otras posibles fuentes del aumento de productividad en el siglo XVIII se muestran igualmente esquivas. Se logró cierto aumento gracias

${ }^{24}$ Para México se ha estimado el potencial de trabajo de las minas entre 33.000 (Humboldt) y 45.000 (Brading). El máximo de producción de 1803 fue de 27 millones de pesos. Así, pues, la producción por trabajador era de entre 600 y 818 pesos. En Perú, Fisher ha calculado la producción por trabajador en 677 pesos en 1799. Véanse Brading (1971), 146; Fisher (1977), 193-194. En términos per capita, sin embargo, la industria peruana era menor, produciendo $4,77^{\star}$ pesos por habitante en 1800 , mientras que la mexicana produjo 6,20 pesos per capita en aquel mismo año.

${ }^{25}$ Salvucci (1987).

${ }^{26}$ Thomson (1986).

${ }^{27}$ TePaske (1985).

2s North y Thomas (1974), cap. 2.

29 Faltan totalmente estudios longitudinales sobre la eficiencia del mercado y de la organización económica, aunque se están acumulando los datos ofrecidos en trabajos que tratan sobre otros aspectos de la actividad económica del siglo xviII. Para un excelente estudio con información nueva sobre el desarrollo de las relaciones crediticias y la organización comercial, véase Kicza (1983).

${ }^{30}$ Van Young resume la evidencia que muestra un apreciable incremento en el cultivo de cereales $y$ otros tipos más intensivos de aprovechamiento de la tierra en la zona central de México, y el simultáneo desplazamiento de la cría de ganado hacia el Norte durante la segunda mitad del siglo xvirI (1986).' Pero Van Young no habla de este proceso como prueba de una especialización regional dirigida al estímulo de la productividad y, en efecto, los datos son excesivamente fragmentarios para verificar esta hipótesis. 
a una mayor especialización regional en producción agrícola, aunque parece haber quedado restringido por los elevados costes de transporte y es probable que a fines del siglo se hubiera esfumado del todo ${ }^{30}$. Probablemente se lograron nuevos aumentos por el desplazamiento de la mano de obra a ocupaciones urbanas, mineras e industriales, abandonando la agricultura, en el transcurso del siglo, pero siendo un 80 por 100 o más de la población activa el que seguía empleado en la agricultura en el año 1800 , no pudieron ser aumentos sustanciales ${ }^{31}$. Sea como fuere, la depresión de fines del xviII pudo muy bien haber eliminado cualesquiera que fueran los pequeños avances logrados anteriormente en este mismo siglo.

El significado del siglo xvirr en la historia económica de Europa occidental y Norteamérica lo convierte en un período especialmente crítico para México. En 1800, la renta per capita mexicana, en la medida en que puede conocerse, era aproximadamente la mitad de la de Estados Unidos y un tercio de la Gran Bretaña ${ }^{32}$. Supongamos que estas tres economías hubieran sido igualmente productivas, es decir, que todas hubieran alcanzado niveles comparables de producto per capita hacia 1700. Supongamos además que la economía de México hubiera crecido a razón igual (pero no superior) al aumento de población, esto es, a algo más de la mitad de 1 por 100 anual (pero cero en términos per capita). Entonces, para que Estados Unidos y Gran Bretaña alcanzaran los niveles de superioridad productiva sobre México observados en 1800, tendrían que haber tenido una tasa anual de crecimiento en renta per capita del 0,7 y el 1,1 por 100 , respectivamente. Estas tasas son, en realidad, muy parecidas a las presentadas como plausibles por los historiadores en ambos casos ${ }^{33}$. Por consiguiente, hasta que sean asequibles datos y procedimientos de estimación mejores, yo me inclino a concluir que los orígenes del moderno subdesarrollo de México se encuentran en el siglo que hemos celebrado, hasta muy recientemente, como «edad de oro» de México.

Si efectivamente la economía mexicana estaba pasando por dificultades, posiblemente decayendo sostenidamente, desde la década de 1780 a 1810 , la contracción que coincidió con las guerras de independencia fue acusada y decisiva. Tras la independencia, como es sabido, la economía se estancó prácticamente hasta la restauración de la república en 1867, un período de casi medio siglo. Yo he calculado que entre 1800 y aproximadamente 1860,

\footnotetext{
"Sobre la distribución de mano de obra, véase Coatsworth (de próxima aparición).

12 Coatsworth (1978).

${ }^{33}$ Para Estados Unidos, véase Lee y Passell (1979), 19-26. Sobre el caso británico, véase Deane y Cole (1962), 282, 329-330.
} 
la producción total descendió tan sólo un 5 por $100^{34}$. Ahora bien, en términos per capita, la caída fue mucho más pronunciada es posible que hasta de un 30 por 100. A lo largo de más de medio siglo, la actividad económica mexicana se estancó, mientras que Europa occidental y Estados Unidos alcanzaban tasas de crecimiento económico sin precedentes. La economía mexicana, con una producción que era la mitad de la de Estados Unidos en 1800, tuvo una productividad en 1867 de sólo la octava parte de la misma. $\mathrm{Y}$ en este punto, con pequeñas variaciones, se ha mantenido desde entonces ${ }^{35}$.

El siglo xix, pues, merece la fama de edad negra que tiene en la historiografía económica mexicana. La lamentable acción de la economía sólo es. comparable a la igualmente desastrosa falta de datos y análisis empíricos. Recientemente, sin embargo, una serie de historias regionales, muchas de ellas elaboradas por investigadores de unos cuantos centros de investigación histórica no emplazados en la Ciudad de México, han empezado a llenar el vacío ${ }^{36}$. Estos trabajos nuevos están comenzando a dar mayor relieve a las importantes variaciones regionales en actividad económica y desarrollo institucional que tuvieron continuidad (o se desviaron de anteriores formas) tras la independencia. Han empezado a aparecer, asimismo, estudios monográficos de industrias o empresas familiares, como el excelente trabajo de David Walker sobre los Martínez del Río ${ }^{37}$. Pero ninguno de ellos ha puesto en cuestión las tristes imágenes de decadencia económica que hemos heredado de los observadores coetáneos.

$Y$ ahora la lista prometida.

1. En primer lugar, hacen falta más y mejores cifras. Los datos fiscales de la época colonial que nos han proporcionado Klein, TePaske, la Fundación Tinker y sus colaboradores han supuesto una enorme contribución a nuestros conocimientos del pasado económico de América Latina, y también a nuestras posibilidades de comprender los orígenes de las dificultades actuales de la región ${ }^{38}$. Y lo mismo puede decirse de Robert Potash y sus colaboradores, que procesaron los fondos del archivo notarial de la Ciudad de México para tres años completos y los pusieron a disposición de los investigadores ${ }^{39}$.

34 Coatsworth (1978).

${ }^{35}$ Los datos comparativos del PNB están publicados en muchos sitios; véase, por ejemplo, U. S. Department of Commerce (1987), 842.

${ }_{36}$ Véanse, por ejemplo, Centro de Investigaciones (1983); los ensayos de Von Mentz, Huerta y Crespo (1984); El Colegio de Michoacán (1981).

37 Walker (1987).

3e TePaske (1976); Klein y TePaske (en prensa); Klein y TePaske (1982).

30 Potash (comp.) (1984). 
Tendría que ser ya posible, al menos para México, trabajar a partir de estos esfuerzos precursores por elaborar compilaciones fiables de datos seriales sobre precios, comercio exterior y producción minera y agrícola de la época colonial, así como de las variables fiscales y económicas hasta el siglo xIx. Este es mi mensaje para el sector de fundamentos.

2. La historiografía del México colonial y del siglo xIX se ha emancipado, avanzando a pasos imperceptibles durante el pasado decenio, de la vulgar idea errónea de que los precios (y el comportamiento del mercado en general) constituyen epifenómenos sin sentido que laten sobre la superficie de los modos de producción precapitalistas (una idea que Marx habria considerado irrisoria, por cierto). Sin una suficiente información sobre precios, la mayor parte de los datos cuantitativos económicos de que disponemos no pueden utilizarse de modo efectivo. Los datos para elaborar series de precios históricas son abundantes, desde los documentos de empresas e instituciones determinadas (haciendas, compañías mercantiles, compañías mineras, conventos y otros semejantes) hasta registros fiscales y otros documentos oficiales. Lo que ahora necesitamos son índices de precios suficientes para permitirnos apreciar su importancia en todos los aspectos del trabajo de historia económica.

3. Necesitamos también más estudios microeconómicos de la productividad de los diversos tipos de actividad económica en la época colonial y en el siglo xIx. El principal defecto de las historias empresariales y rógionales de México es que no llegan a abordar la cuestión de la productividad ni a calibrarla. Sólo uno de entre las docenas de estudios sobre haciendas que han aparecido en los últimos veinte años plantea al menos este aspecto. 1 Ward Barret descubrió que la producción hombre/día en la hacienda azucarera de la familia Cortés aumentó de modo impresionante entre tines del siglo XVI y mediados del xvIII, un descubrimiento que debiera haber conmocionado este campo, pero que ha pasado casi totalmente inadvertido ${ }^{40}$. Ninguno de los estudios de la industria minera publicados en la última década ha intentado medir los cambios de productividad del capital o la mano de obra. Los estudios de la industria textil, empezando por el de Bazant, han planteado la cuestión pero han avanzado escasamente en ella ${ }^{41}$. Nuestra comprensión de muchos misterios macroeconómicos se vería considerablemente acrecentada por trabajos que acometieran esta cuestión en el ámbito de las empresas productivas.

\footnotetext{
* Barrett (1970).

4 Bazant (1962). Steven Haber ha iniciado recientemente un importante proyecto de investigación para comparar la productividad de las industrias textiles algodoneras de México, Brasil y Estados Unidos en el siglo xix.
} 
4. Acaso sea ya momento de empezar a tratar la depresión del siglo xIX que comenzó en el xviII y se prolongó hasta la década de 1870 como una unidad. Yo sugeriría que los directores de tesis y los asesores de editoriales declaren una moratoria de diez años para todos los trabajos que terminen en 1810. ¡Y los epílogos no cuentan!

5. También es hora, a mi juicio, de revivir una antigua tradición de estudios de historia legal que terminó, al menos en México, con la revolución de 1910. Si el subdesarrollo de México a comienzos de la época contemporánea se debe, al menos parcialmente en mi opinión, a un orden institucional arcaico, entonces la historia del derecho y la jurisprudencia comerciales tendrían que tener un puesto destacado en nuestra lista de áreas de investigación decisivas ${ }^{42}$.

6. Hace falta mucha más historia económica comparativa. El modo más eficaz de disciplinar el uso de terminología cualitativa en los trabajos de historia económica es por medio de la comparación. El desarrollo de la historia económica cuantitativa en Estados Unidos, Europa occidental y en toda América Latina posibilita hoy día la comparación de la actividad micro y macroeconómica de México con las de otros países. Cada cifra hallada, cada modelo inventado debe contrastarse con los datos y la interpretación elaborados por estudiosos especialistas en la historia económica de otros países, reales o contrafactuales.

7. Finalmente, necesitamos modelos macro-históricos plausibles. Habremos salido de la era de la teoría de la dependencia, los modos de producción y los sistemas mundiales, pero no hemos descubierto aún modelos más plausibles para sintetizar la evolución general de la formación social mexicana en modos que generen hipótesis susceptibles de investigación para la historia económica. Esta muy bien eso de "volver a insertar el Estado», como nos exigían hace unos años nuestros colegas de las ciencias sociales ${ }^{43}$, pero ¿dónde volvemos a insertar el Estado?

${ }^{42}$ La reciente renovación de interés en la historia legal de México es un buen augurio, aunque las complejidades del derecho comercial, en aspectos tan especializados como patentes, minería, banca y seguros, siga siendo objeto de menor atención que el derecho civil o constitucional.

${ }_{43}$ Evans, Rueschemeyer y Skocpol (eds.) (1985), en especial su ensayo de conclusión. 


\section{BIBLIOGRAFIA}

Aguirre Beltrán, Gonzalo (1946): La población negra de México, 1518-1810 (México, Ediciones Fuente Cultural).

BARRETT, Ward (1970): The Sugar Hacienda of the Marqueses del Valle (Minneapolis, University of Minnesota Press).

BAzANT, Jan (1962): «Estudio sobre la productividad de la industria algodonera mexicana en 1843-45 (Lucas Alemán y la revolución industrial de México)», en La industria nacional y el comercio exterior (1842-1851) (México, Banco Nacional de Comercio Exterior).

Bora H, Woodrow (1951): New Spain's Century of Depression, Ibero-Americana, núm. 35 (Berkeley, University of California Press).

Bora H, Woodrow, y Cook, Sherburne F. (1960): The Indian Population of Central Mexico, 1531-1605, Ibero-Americana, núm. 44 (Berkeley, University of California Press).

- (1979): Essays in Population History: Mexico and California, 3 vols. (Berkeley, Unj. versity of California Press).

Brading, David A. (1971): Miners and Merchants in Bourbon Mexico: 1763-1810 (Cambridge, Cambridge University Press).

Braudel, Fernand, y Spooner, Frank (1967): «Prices in Europe from 1450 to 1750», en The Cambridge Economic History of Europe, editada por E. E. Rich y C. H. Wilson (Cambridge, Cambridge University Press).

Centro de Investigaciones Históricas y Sociales (1983): Puebla en el siglo XIX: contribución al estudio de su bistoria (Puebla. Centro de Investigaciones Históricas y Sociales, Instituto de Ciencias, Universidad Autónoma de Puebla).

Contswort H, John H. (1978): «Obstacles to Economic Growth in Nineteenth-Century Mexico», American Historical Review, 83: 1. (Hay traducción española.)

- (de próxima aparición): «The Decline of the Mexican Economy, 1800-1860».

- (1986): «The Mexican Mining Industry in the Eighteenth Century», en Nils Jacobsen y Hans-Jürgen Puhle.

- (1982): «The Limits of Colonial Absolutism: The State in Eighteenth-Century Mexi. cow, en Essays in the Political, Economic and Social History of Colonial Latin America, editado por Karen Spalding (Newark, Delaware, University of Delaware Latin American Studies Program, Occasional Papers and Monographs, núm. 3).

Deane, Phyllis, y Cole, W. A. (1962): British Economic Growth, 1688-1959: Trends and Structure (Cambridge, Cambridge University Press).

El Colegro de Mich oncán (1981): Memoria del III Coloquio de Antropología e Historia Regionales: La desintegración de la gran propiedad agraria de México (Zamora, El Colegio de Michoacán).

Evans, Peter; Ruesc h emeyer, Dietrich, y Skocpol, Theda (eds.) (1985): Bringing the State Back In (Cambridge, Cambridge University Press).

Frs H ER, John (1977): Minas y mineros en el Perú colonial, 1776-1824 (Lima, Instituto de Estudios Peruanos).

Florescano, Enrique (1969): Precios del maíz y crisis agricolas en México (1709-1810) (México, El Colegio de México).

Florescano, Enrique, y Gil, Isabel (1976): «1750-1808: La época de las reformas borbónicas y del crecimiento económico», en Historia general de México, editada por el Centro de Estudios Históricos de El Colegio de México, 4 vols. (México, El Colegio de México).

Galicia, Silvia (1975): Precios y producción en San Miguel el Grande, 1661-1803 (Mexico, Instituto Nacional de Antropología e Historia, Departamento de Investigaciones Históricas).

JACOBSEn, Nils, y Puhle, Hans-Jürgen (eds.) (1986): The Economies of Mexico and Peru During the Late Colonial Period, 1760-1810 (Berlin, Colloquium Verlag).

KAMEN, Henry, e IsRaEL, J. I. (1982): ensayos en «Debate: The Seventeenth-Century Crisis in New Spain: Myth or Reality? $\$$, Past and Present, 97. 
KICzA, John E. (1983): Colonial Entrepeneurs: Families and Business in Bourbon Mexico City (Alburquerque, University of New Mexico Press).

KLEIN, Herbert R. (1985): «The Economy of New Spain, 1680-1809: The View from the Royal Treasuries» (manuscrito no publicado).

KLEIN, Herbert R., y TEPASKE, John J. (1981): "The Seventeenth-Century Depression in New Spain: Myth or Reality?*, Past and Present, 90.

- (en prensa): Ingresos y egresos de la Real Hacienda de México, 3 vols. (México, Instituto Nacional de Antropología e Historia).

- (1982): Royal Treasuries of the Spanish Empire in America, 3 vols. (Durham, N.C., Duke University Press).

Lez, Susan Previant, y Passeld, Peter (1979): A New Economic View of American History (Nueva York, W. W. Norton).

LINDLEY, Richard B. (1982): Kinship and Credit in the Structure of Guadalajara's Oligarchy, 1800-1830 (Austin, University of Texas Press).

MorIN, Claude (1979): Michoacán en la Nueva España del siglo XVIII. Crecimiento y desigualdad en una economia colonial (México, Fondo de Cultura Económica).

NoRT H, Douglas, y Thomas, Robert Paul (1974): The Rise of the Western World: A New Economic History (Cambridge, Cambridge University Press). (Hay traducción española.)

Parker, Geoffrey, y Smit h, Leslie (eds.) (1978): The General Crisis of the Seventeenth Century (Londres, Routledge and Kegan Paul).

PASTOR, Rudolfo, et al. (1979): Fluctuaciones económicas en Oaxaca durante el siglo XVIII (México, El Colegio de México).

Poras H, Robert A. (comp.) (1984), con la colaboración de Jan Bazant y Josefina Z. Vázquez: Guide to the Notarial Records of the Archivo General de Notarias, Mexico City, for the Years 1829, 1847, 1875, 3 vols. (Amherst, University of Massachusetts Press).

Salvucc1, Richard J. (1987): Textiles and Capitalism in Mexico: An Economic History of the Obrajes, 1539-1830 (Princeton, Princeton University Press).

Semo, Enrique (1975): «Las revoluciones en la historia de México», Historia y Sociedad, 8.

TAYLOR, William B. (1972): Landlord and Peasant in Colonial Oaxaca (Stanford, Stanford University Press).

TePaske, John J. (1976): La real bacienda de Nueva España: la real caja de México (1576-1816) (México, Instituto Nacional de Antropología e Historia, Departamento de Investigaciones Históricas, Colección Científica, Fuentes, núm. 41).

- (1985): "Economic Cycles in New Spain in the Eighteenth Century: The View from the Public Sector», en Iberian Colonies, New World Societies: Essays in Memory of Charles Gibson, editado por Richard L. Garner y William B. Taylor.

- (1986): «General Tendencies and Secular Trends in the Economies of Mexico and Peru, 1750-1810: The View from the Cajas of Mexico and Limam, en Jacobsen $y$ Puhle.

Tromson, Guy (1986): «The Cotton Textile Industry in Puebla During the Eighteenth and Early Nineteenth Centuries», en Jacobsen y Puhle.

U. S. Depart MenT OF Commerce, Bureau of the Census (1987): Statistical Abstract of the United States 1986: National Data Book and Guide to Sources (Washington, D. C., Government Printing Office).

VAN Young, Eric (1981): Hacienda and Market in Eighteenth-Century Mexico: The Rural Economy of the Guadalajara Region, 1675-1820 (Berkeley, University of California Press).

X - (1986): «The Age of Paradoxes: Mexican Agriculture at the End of the Colonial Period, 1750-1810\%, en Jacobsen y Puhle.

Von Menz, Brígida; Huerta, María Teresa, y CRespo, Horacio (1984): ensayos en Mo relos: cinco siglos de su historia, editado por Horacio Crespo (Cuernavaca, Centro de Estudios Históricos del Agrarismo de México, Universidad Autónoma del Estado de

Morelos).
W WLKer, David W. (1987): Kinship, Business and Politics: The Martinez del Río Family in Mexico, 1823-1867 (Austin, University of Texas Press). 